\title{
Analisis Risiko Produksi Cabai Merah di Desa Margototo Kecamatan Metro Kibang Kabupaten Lampung Timur
}

\section{Production Risk Analysis of Red Chillies in Margototo Village Kibang Metro District of East Lampung Regency}

\author{
Ainul Mardliyah* dan Priyadi \\ Dosen Pengajar di STIPER Dharma Wacana Metro \\ Jln Kenanga No 3 Mulyojati 16C Metro, Kota Metro \\ E-mail : ainulsoekoyo@gmail.com
}

\begin{abstract}
This research to analyze the risk of red chili production in Margototo Village Metro Kibang District East Lampung Regency. This research was conducted in Margototo Village Metro Kibang District East Lampung Regency. Methods Sampling was conducted using a simple random sampling method. With a sample of 37 farmers who participate in farmer groups that cultivate red chili. This research was conducted from December 2020 to January 2021. Coefficient of Variation (CV) analysis were used $t$ answer. The results showed that the production risk of red chili farming in Maragoto Village Metro Kibang District East Lampung Regency had a low risk with a coefficient of variation for production risk of 0.31 .
\end{abstract}

Keywords: chili, production, risk.

Disubmit : 19 Juni 2021, Diterima: 28 Oktober 2021, Disetujui : 29 Oktober 2021

\section{PENDAHULUAN}

Indonesia merupakan salah satu negara berkembang yang memiliki sumber daya alam yang melimpah dimana sebagian besar penduduknya bermata pencaharian sebagai petani. Salah satu sub sektor pertanian yang menjadi pusat perhatian adalah sub sektor pangan dan hortikultura. Dalam mendorong pertumbuhan pertanian, salah satu komoditas hortikultura yang diprioritaskan yaitu cabai. Sehingga pengembangan terhadap komoditas cabai terus ditingkatkan agar produksi stabil, karena masyarakat Indonesia rata rata mengkonsmusi cabai merah. Hal ini sejalan dengan (WIDYANTARA, 2016) bahwa konsumsi cabai merah di Indonesia diperkirakan 1, $40 \mathrm{~kg}$ per kapita/tahun.

Pengembangan usaha di bidang pertanian khususnya cabai merah memiliki risiko produksi karena bergantung pada alam sehingga produktivitas rendah dan tidak stabil yang menyebabkan tingginya peluang terjadinya kegagalan produksi, hal ini senada dengan (Ekaria dan Muhammad, 2018) risiko produksi berdampak pada kegagalan panen atau penurunan jumlah hasil panen dari hasil panen yang diharapkan. Hal ini menjadikan cabai merah memiliki potensi risiko produksi yang dihadapi oleh petani. produksi cabai merah mengalami keseimbangan dalam jumlah produksinya setiap tahunnya, hal ini yang membuat petani selalu menanam cabai merah walaupun harganya mengalami fluktuasi. Kabupaten Lampung Timur memiliki 
produksi cabai merah sebesar 2.502 ton (BPS Provinsi Lampung, 2018) yang artinya Kabupaten Lampung Timur merupakan salah satu penghasil cabai merah (sentra produksi) di Provinsi Lampung.

Kecamatan Metro Kibang merupakan salah satu tempat yang menghasilkan produksi cabai di Kabupaten Lampung Timur. Produksi cabai merah di Kecamatan Metro Kibang berada pada di Desa Margototo. Keterbatasan pengetahuan yang dimiliki petani dalam upaya meningkatkan produksinya seringkali menjadi hambatan yang sering mengakibatkan penggunaan faktor-faktor produksi menjadi suatu kombinasi yang kurang tepat yang dapat mempengaruhi pendapatan, hal ini senada dengan penelitian (Eliyatiningsih \& Mayasari, 2019) yang menyatakan bahwa dalam melakukan usahatani petani dapat mengalokasikan faktor produksi sehingga usahatani yang dijalankan dapat memberikan pendapatan yang optimal.

Usahatani cabai merah merupakan usaha yang dilakukan di Kecamatan Metro Kibang, melihat potensi yang ada maka peranan sektor pertanian dalam rangka bekerja sama terhadap peningkatan pendapatan petani cabai merah melalui peningkatan produksi sangat penting, akan tetapi ada beberapa kendala yang menjadi risiko dalam berproduksi cabai merah yang harus ditanggung oleh petani. Adapun produksi cabai merah di Kecamatan Metro kibang pada tahun 2019 menurut Dinas Pertanian sebesar 4.632 ton dengan luas lahan sebesar 475 ha. Pada tahun ini produksi cabai di Kecamatan Metro Kibang mengalami penurunan karena serangan hama dan penyakit serta fluktuasi harga cabai yang menjadi risiko petani dalam berusahatani cabai merah di Desa Margototo Kecamatan Metro Kibang Kabupaten Lampung Timur, sehingga peneliti ingin menganalisis risiko produksi petani cabai merah di Desa Margototo Kecamatan Metro Kibang Kabupaten Lampung Timur.

\title{
METODE PENELITIAN
}

Penelitian ini dilakukan di Desa Margototo Kecamatan Metro Kibang Kabupaten Lampung Timur. Lokasi penelitian ditentukan secara sengaja (purposive) dengan pertimbangan bahwa daerah tersebut memiliki lahan yang luas dalam usahatani cabai merah di Kabupaten Lampung Timur. Pelaksanaan penelitian dilakukan pada bulan Desember 2020 hingga Januari 2021. Pengambilan sampel dalam penelitian ini dilakukan dengan metode pengambilan sampel secara acak (simple random sampling) dengan jumlah sampel sebanyak 37 petani yang ikut dalam kelompok tani yang membudidayakan cabai merah. Untuk menjawab tujuan penelitian dengan menggunakan Koefisien Variasi (CV) dengan rumus sebagai berikut :

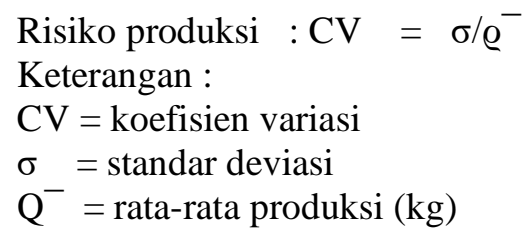

Besarnya nilai koefisien variasi menunjukkan besarnya risiko relatif usahatani. Nilai koefisien variasi kecil menunjukkan variabilitas nilai rata-rata pada karakteristik yang rendah, menggambarkan risiko yang akan dihadapi petani untuk memperoleh produksi rata-rata kecil ataupun sebaliknya. Penentuan batas bawah ini untuk mengetahui jumlah hasil terbawah tingkat hasil yang diharapkan dengan rumus perhitungan batas bawah sebagai berikut

$$
\mathrm{L}=\mathrm{E}-2 \mathrm{~V}
$$

Keterangan :

$\mathrm{L}=$ Batas bawah produksi

$\mathrm{V}=$ Standar deviasi (simpangan baku)

$\mathrm{E} \quad=$ rata-rata produksi yang diperoleh

\section{HASIL DAN PEMBAHASAN}

\author{
Usahatani Cabai Merah \\ Penggunaan Benih dan Pupuk
}

Hal 94 Volume 5, Nomor 2, Tahun 2021 
Benih yang digunakan pada wilayah penelitian ada dua jenis yaitu benih hibrida dan benih lokal (non hibrida). Pemilihan benih hibrida yang merupakan benih unggul merupakan awal keberhasilan untuk meningkatkan produksi cabai merah melalui peningkatan potensi produksi. Benih hibrida yang digunakan oleh petani cabai yakni benih Lado, Kresna, dan Panah Merah. Petani memilih benih ini karena memiliki keunggulan dari varietas yang lain dan cocok dengan tanah di Desa Margototo. Sedangkan benih lokal (non hibrida) digunakan petani karena mahalnya biaya untuk membeli benih hibrida sehingga petani menggunakan benih lokal yang memiliki kualitas yang bagus dan unggul. Hal ini senada dengan penelitian (Marleen et al., 2018) yang menyatakan bahwa cara pemilihan bibit unggul yang tepat sesuai dengan kriteria yang diinginkan. Besar kecilnya penggunaan bibit disebabkan adanya perbedaan luas lahan yang digarap, rata-rata penggunaan benih dalam satu kali musim tanam yaitu 84,59 gram/usahatani. Petani mendapatkan benih cabai merah dari kios-kios resmi yang telah ditunjuk oleh masing-masing kelompok tani.

Petani cabai merah di Desa Margototo menggunakan pupuk kimia seperti pupuk Za, pupuk Ponska, pupuk KCL, pupuk SP36, pupuk mutiara, pupuk kandang. Rata-rata penggunaan pupuk oleh petani responden di Desa Margototo Kecamatan Metro Kibang dapat dilihat pada Tabel 1.

Tabel 1. Rata-rata penggunaan pupuk dalam per Usahatani di Desa Margototo Kecamatan Metro Kibang, 2021 (dalam kg)

\begin{tabular}{clc}
\hline No & Jenis Pupuk & Jumlah $(\mathrm{kg} / \mathrm{ha})$ \\
\hline 1 & Za & 28,91 \\
2 & Phonska & 197,29 \\
3 & KCL & 70,27 \\
4 & SP36 & 148,65 \\
5 & Mutiara & 46,62 \\
6 & Kandang & $2.690,54$ \\
\hline
\end{tabular}

Sumber: Data Primer, 2021

Berdasarkan Tabel 1 diketahui bahwa penggunaan pupuk kimia oleh petani cabai merah di Desa Margototo yang paling banyak adalah pupuk ponska. Penggunaan pupuk yang berlebih dapat mengakibatkan biaya produksi naik sehingga pendapatan petani berkurang. Pemupukan diperlukan agar tanaman dapat memenuhi unsur hara yang diperlukan oleh tanaman sehingga dapat meningkatkan produktivitas cabai merah, hal ini senada dengan penelitian (Yuniarti et al., 2019) yang menyatakan bahwa unsur hara merupakan salah satu faktor yang dapat menentukan produktivitas. Pemupukan yang dilakukan hendaknya memperhatikan kebutuhan tanaman, hal ini senada dengan penelitian (Ernita et al., 2021) yang mengatakan bahwa pemupukan tanaman sangat penting dilakukan sesuai dengan kebutuhan tanaman. Pemupukan yang tidak sesuai dengan kebutuhan tanaman menghasilkan produksi yang tidak maksimal.

\section{Penggunaan Pestisida}

Obat-obatan dalam usahatani cabai merah digunakan untuk memberantas serangan hama dan penyakit tanaman. Penggunaan obat-obatan di daerah penelitian bervariasi tergantung jenis hama dan penyakit yang menyerang. Petani responden menggunakan obat-obatan yang beragam tergantung kondisi dari tanaman yang terserang hama dan penyakit yang dapat dilihat pada Tabel 2.

Tabel 2. Rata-rata dosis penggunaan obat-obatan oleh petani responden di Desa Margototo, 2021.

\begin{tabular}{lc}
\hline Jenis obat-obatan & Jumlah penggunaan obat-obatan \\
\hline Herbisida & $7,21 \mathrm{Kg}$ \\
Insektisida & $1,33 \mathrm{Liter}$ \\
Fungisida & $2,46 \mathrm{Kg}$ \\
\hline
\end{tabular}

Berdasarkan tabel 2 terlihat bahwa penggunaan pestisida yang paling banyak digunakan oleh petani cabai di Desa Margototo yakni Herbisida, hal ini dikarenakan banyaknya gulma yang tumbuh di waktu dan kondisi yang tidak diinginkan petani. Sedangkan fungisida digunakan untuk memberantas jamur berupa Antracol dan Mankozeb yang banyak digunakan oleh petani cabai karena lebih efektif terhadap penyakit. Hal 
ini senada dengan penelitian (Sila \& Sopialena, 2016) yang menyatakan bahwa fungisida antracol memiliki spectrum pembunuh penyakit lebih kuat dari fungisida lainnya.

\section{Penggunaan tenaga kerja}

Tenaga kerja merupakan faktor produksi yang sangat penting dalam mengelola usahatani. Penggunaan tenaga kerja dalam usahatani cabai merah berasal dari dalam keluarga dan luar keluarga.Tenaga kerja tersebut digunakan untuk melakukan kegiatan mulai dari awal yaitu pengolahan lahan, sampai dengan pasca panen.Penggunaan tenaga kerja untuk usahatani cabai merah dapat dilihat pada Tabel 3.

Tabel 3. Penggunaan Tenaga Kerja Rata-rata petani responden Cabai Merah di Desa Margototo Tahun 2021.

\begin{tabular}{lccc}
\hline Jenis Pekerjaan & \multicolumn{2}{c}{ Tenaga Kerja } & \\
\cline { 2 - 4 } & TKDK (Hok) & TKLK (Hok) & Total Hok \\
\hline Olah Lahan & 5,35 & 6,57 & 11,92 \\
Penyemaian & 1,99 & 2,01 & 4,00 \\
Penanaman & 2,59 & 6,14 & 8,73 \\
Penyiangan & 2,50 & 1,98 & 4,48 \\
Penyiraman & 0,42 & 0,24 & 0,66 \\
Penyemprotan & 0,87 & 0,29 & 1,16 \\
Pemupukan & 1,40 & 2,21 & 3,61 \\
Panen & 2,20 & 5,25 & 7,45 \\
\hline Jumlah & 17,32 & 24,69 & 42,01 \\
\hline
\end{tabular}

Berdasarkan Tabel 3 Menunjukkan bahwa Total Rata-rata Per usahatani Cabai Merah adalah 42,01 per usahatani. Tenaga kerja yang digunakan lebih banyak berasal dari luar keluarga, kebutuhan tenaga kerja terbesar yaitu pada kegiatan pengolahan lahan, penanaman bibit, dan panen. Kegiatan pemanenan sebaiknya dilakukan tepat pada waktunya, panen yang tidak tepat waktu akan menurunkan produksi karena buah cabai akan membusuk karena umur simpan cabai yang pendek, hal ini senada dengan penelitian (David, 2018) yang menyatakan bahwa umur simpan cabai yang cukup pendek yaitu sekitar lima hari. Penggunaan tenaga kerja di lokasi penelitian adalah tenaga kerja pria dan wanita, baik di dalam keluarga dan luar keluarga yang dihitung dengan hari orang kerja (hok). Hal ini selaras dengan penelitian (Mardliyah, 2019) yang menyatakan bahwa tenaga kerja terdiri dari tenaga kerja wanita dan tenaga kerja pria yang disama ratakan dengan satuan hari orang kerja (hok).

\section{Risiko Produksi Cabai Merah}

Risiko produksi cabai merah dapat dianalisis dengan menggunakan analisis koefisien variasi (CV). Analisis koefisien variasi merupakan perbandingan antara nilai standar deviasi dengan nilai rata-rata atau dengan nilai yang diharapkan sehingga diketahui besarnya risiko relatif produksi pada usahatani cabai merah.

Nilai efisien variasi yang lebih menunjukkan nilai rata-rata pada karakteristik tersebut dinilai rendah. Nilai tersebut menggambarkan risiko yang dihadapi dalam memperoleh pendapatan yang lebih kecil, dan sebaliknya nilai efisien variasi (CV) yang lebih besar menunjukkan nilai rata-rata pada karakteristik tersebut tinggi yang menggambarkan risiko yang dihadapi lebih besar. Risiko produksi usahatani cabai merah sesuai tabel 4 .

Tabel 4. Risiko Produksi Pada Usahatani Cabai merah di Desa Margototo Kecamatan Metro Kabupaten Lampung Timur.

\begin{tabular}{lc}
\hline \multicolumn{1}{c}{ Uraian } & Usahatani cabai merah \\
\hline Rata-rata produksi (kg/ha) & $2.758,00$ \\
Standar Deviasi & 868,43 \\
Batas Bawah (L) & $1.017,12$
\end{tabular}

Hal 96 Volume 5, Nomor 2, Tahun 2021 
Penulis : Ainul M, dkk, Analisis Risiko Produksi Cabai Merah di Desa Margototo Kecamatan Metro Kibang Kabupaten Lampung Timur

\begin{tabular}{lr} 
Koefisien Variasi (CV) & 0,31 \\
CV $(\%)$ & 31 \\
\hline
\end{tabular}

Sumber : Analisis Data Primer, 2021

Berdasarkan Tabel 4 memperlihatkan bahwa rata-rata produksi usaha tani cabai merah sebesar 2.758 $\mathrm{kg} / \mathrm{Ha}$. Kemudian batas bawah produksi sebesar 1.017,12 yang artinya bahwa kemungkinan risiko produksi terendah petani cabai merah per usahatani setiap musim tanam sebesar 1.017,12 kg/usahatani, hasil perhitungan Koefisien Variasi (CV) produksi cabai merah sebesar 0,31 artinya peluang kerugian yang dihadapi oleh responden sebesar 31 persen yang disebabkan adanya perubahan cuaca, serangan hama dan penyakit sehingga risiko produksi yang ditanggung petani cabai merah lebih dari 31 persen. Artinya risiko yang dihadapi petani rendah, tetapi petani tetap harus menanggung risiko karena perubahan cuaca dan serangan hama penyakit yang menyebabkan petani semakin besar dalam penggunaan sarana produksi yang dapat menyebabkan berkurangnya pendapatan petani, hal ini sejalan dengan penelitian (Misqi \& Karyani, 2020) yang menyatakan bahwa semakin besar penggunaan sarana produksi maka semakin tinggi korbanan biaya yang harus dikeluarkan petani.

\section{KESIMPULAN DAN SARAN \\ Kesimpulan}

Berdasarkan hasil penelitian dan pembahasan maka dapat disimpulkan bahwa: risiko produksi pada usahatani cabai merah di Desa Maragototo Kecamatan Metro Kibang Kabupaten Lampung Timur memiliki risiko yang rendah dengan nilai koefisien variasi untuk risiko produksi sebesar 0,31.

\section{Saran}

Berdasarkan hasil dan pembahasan, maka saran yang diajukan dalam penelitian ini adalah: Pemerintah daerah hendaknya harus lebih banyak memberikan penyuluhan tentang budidaya cabai merah dengan menggunakan benih hibrida kepada petani karena banyak petani cabai merah yang menggunakan benih padi lokal/non hibrida sehingga risiko produksi semakin kecil.

\section{UCAPAN TERIMA KASIH}

Penulis mengucapkan terima kasih kepada STIPER Dharma Wacana Metro atas bantuan biaya pada penelitian ini.

\section{DAFTAR PUSTAKA}

BPS Provinsi Lampung. (2018). Provinsi Lampung Dalam Angka 2018. https://lampung.bps.go.id/publication/2018/08/16/8a37f460958edf158a0314de/provinsi-lampungdalam-angka-2018.html

David, J. (2018). Teknologi untuk memperpanjang masa simpan cabai. Jurnal Pertanian Agros, 20(1), 22 28. http://download.garuda.ristekdikti.go.id/article.php?article=761606\&val=12307\&title=TECHNOLOG Y TO LENGTHEN OF STORAGE OF CHILI

Ekaria, E., \& Muhammad, M. (2018). Analisis Risiko Usahatani Ubi Kayu di Desa Gorua Kecamatan Tobelo Utara. Agrikan: Jurnal Agribisnis Perikanan, 11(2), 9-14. https://doi.org/10.29239/j.agrikan.11.2.9-14

Eliyatiningsih, E., \& Mayasari, F. (2019). Efisiensi Penggunaan Faktor Produksi pada Usahatani Cabai Merah di Kecamatan Wuluhan Kabupaten Jember. Jurnal Agrica, 12(1), 7. https://doi.org/10.31289/agrica.v12i1.2192

Ernita, M., Alhidayati, A., \& Haryoko, W. (2021). PENGARUH PUPUK NPK DAN NANO PESTISIDA 
SERAIWANGI TERHADAP PERTUMBUHAN DAN HASIL TANAMAN CABAI MERAH (Capsicum annuum L.). AGROTEK: Jurnal Ilmiah Ilmu Pertanian, 4(2), 1-9. https://doi.org/10.33096/agrotek.v4i2.128

Mardliyah, A. (2019). Risiko Produksi Usahatani Padi Di Kabupaten Lampung Timur. Journal of Food System \& Agribusiness, 2(1), 8-16. https://doi.org/10.25181/jofsa.v2i1.1106

Marleen, D. O., Suharni, Ridwan, A., \& Puspita, R. (2018). PERANCANGAN PROTOTIPE APLIKASI PEMILIHAN BIBIT CABAI Seedlings are one of the most important components in growing cayenne pepper . In general, farmers grow cayenne pepper seeds from the seeds they obtained at the time, even though there are many variet. Seminar Nasional Edusainstek, 98-107.

Misqi, R. H., \& Karyani, T. (2020). ANALISIS RISIKO USAHATANI CABAI MERAH BESAR (Capsicum annuum L.) DI DESA SUKALAKSANA KECAMATAN BANYURESMI KABUPATEN GARUT. Mimbar Agribisnis: Jurnal Pemikiran Masyarakat Ilmiah Berwawasan Agribisnis, 6(1), 6575. https://doi.org/10.25157/ma.v6i1.2684

Sila, S., \& Sopialena. (2016). Perkembangan Penyakit dan Produksi Tanaman Cabai ( Capsicum frutescens ) dan Colletotrichum capsici ( Syamsuddin , tanaman. Jurnal AGRIFOR, 15(1), 117-130.

WIDYANTARA, W. (2016). Risiko Produksi Cabai Merah Besar Pada Berbagai Luas Garapan Usahatani. E-Journal Agribisnis Dan Agrowisata (Journal of Agribusiness and Agritourism), 5(2), 488-497.

Yuniarti, A., Damayani, M., \& Nur, D. M. (2019). EFEK PUPUK ORGANIK DAN PUPUK N,P,K TERHADAP C-Organik, N-Total, C/N, SERAPAN N, SERTA HASIL PADI HITAM PADA INCEPTISOILS. Jurnal Pertanian Presisi, 30-104. https://ejournal.gunadarma.ac.id/index.php/jpp/article/download/2205/1952 